\title{
A CATEGORIA TEMPO NA AQUISIÇÃO DO PORTUGUÊS ESCRITO COMO L2 POR SURDOS
}

\section{LA CATEGORÍA TIEMPO EN LA ADQUISICIÓN DEL PORTUGUÉS ESCRITO COMO L2 POR SORDOS}

\author{
THE TENSE CATEGORY IN THE ACQUISITION OF THE PORTUGUESE WRITTEN AS L2 BY \\ DEAF PEOPLE
}

\author{
Adriana Stella Cardoso Lessa-de-Oliveira* \\ Marcelo Meira Alves** \\ Universidade Estadual do Sudoeste da Bahia
}

RESUMO: O presente estudo tem como objeto a categoria Tempo na aquisição do Português Brasileiro escrito por surdos. Para esta investigação, fundamentamo-nos no gerativismo, admitindo a teoria inatista de aquisição da linguagem. No âmbito da aquisição de L2, assumimos a hipótese de acesso indireto à Gramática Universal (GU). Nosso corpus se constitui de amostras naturalísticas textos produzidos em ambiente escolar. Os resultados indicam ocorrência, na interlíngua estudada, de operadores temporais específicos da Libras - os itens lexicais passado e futuro e advérbios. Marcando Tempo passado, observou-se ocorrência de operador lexical em casos de verbos com Aspecto não pontual e a dispensa desse em casos de verbos com Aspecto perfectivo, como ocorre na Libras, conforme estudo de Silva (2015) e Silva e Lessa-de-Oliveira (2016), o que caracteriza acesso indireto à GU no processo de aquisição da L2. As produções escritas também apresentaram flexão temporal conforme o Português Brasileiro e a realização de verbos auxiliares marcando Tempo futuro.

PALAVRAS-CHAVE: Aquisição da linguagem. Categoria tempo. Gramática gerativa.

RESUMEN: El objeto de este estudio es la categoría Tiempo en la adquisición del Portugués Brasileño escrito por personas sordas. Para la investigación, nos basamos en la teoría generativa, admitiendo la hipótesis innatista de la adquisición del lenguaje. En el ámbito de la adquisición de la L2, asumimos la hipótesis de acceso indirecto a la Gramática Universal (GU). Nuestro corpus está constituido por algunas muestras naturalistas - son textos producidos en un ambiente escolar. Los resultados indican que, en la interlengua que se estudió, aparecen elementos temporales específicos de la lengua de señales Libras (Lengua de Señas Brasileña) -

\footnotetext{
* Doutora em Linguística pela Unicamp; Professora Titular do Departamento de Estudo e Linguísticos e Literários da Universidade Estadual do Sudoeste da Bahia - UESB, Docente do Programa de Pós-Graduaça em Linguística PPGLin/UESB. E-mail: adriana.lessa.de.oliveira@gmail.com

** Mestre em Linguística pela Universidade Estadual do Sudoeste da Bahia - UESB; Especialista em Educação Especial: ensino do aluno com deficiência auditiva pelo Centro Universitário Claretiano. E-mail: marcelofilol3@gmail.com.
} 
los elementos léxicos pasado y futuro y adverbios. En el Tiempo pasado, se observó el uso de operador léxico en casos de Aspecto verbal no puntual y su dispensa en el caso de los verbos con Aspecto perfectivo, como ocurre en Libras, según un estudio de Silva (2015) y Silva e Lessa-de-Oliveira (2016), lo que constituye acceso indirecto a la GU en el proceso de la adquisición de la L2. Las producciones escritas también presentaron la flexión temporal de acuerdo a la del Portugués Brasileño y recurrieron al uso de verbos auxiliares para referirse al Tiempo futuro.

PALABRAS CLAVE: Adquisición del Lenguaje. Categoría Tiempo. Gramática Generativa.

ABSTRACT: The present study has as object the category Tense in the acquisition of written Brazilian Portuguese by deaf people. The analysis of the phenomenon of acquisition of the Tense category investigated here was based on the generative theory, assuming the innatist proposition of language acquisition. In the context of the acquisition of L2, we assumed the hypothesis of indirect access to Universal Grammar (UG). Our corpus consists of naturalistic samples - texts produced in a school environment. Results indicate the occurrence of specific temporal operators of Libras (Brazilian sign language) in the interlanguage - the past and future lexical items and certain adverbs. We observed the occurrence of lexical operator for past Tense marking in verbs with non-punctual Aspect and the dispensation of this mark in cases of verbs with perfective Aspect, as occurs in Libras according to a study by Silva (2015) and Silva and Lessa-de-Oliveira (2016). This finding characterizes indirect access to the UG in the process of acquisition of L2. The written productions also displayed temporal flexion according to the parameters of Brazilian Portuguese and the use of auxiliary verbs to mark the future tense.

KEYWORDS: Generative Grammar. Language Acquisition. Tense Category.

\section{INTRODUÇÃO}

A Língua Portuguesa assume, para os surdos, o papel de segunda língua (L2), a qual deve ser utilizada pela comunidade surda não como uma língua alternativa, mas em contextos em que não há como substituí-la pela língua de sinais, como, por exemplo, para acessar material escrito em Português Brasileiro (PB), que guarda uma gama enorme de conhecimento. Sendo assim, é desejável que o bilinguismo seja adotado pela comunidade surda, já que essa não prescinde do uso nem de uma língua gesto-visual (ou de sinais), em modalidade falada, nem da língua oral-auditiva oficial do país, em modalidade escrita.

Este trabalho é resultado de uma pesquisa que teve como objeto a análise da categoria Tempo na interlíngua (IL) Português-Libras adquirida em modalidade escrita por alunos surdos nas classes regulares de ensino. ${ }^{1}$ A pesquisa surgiu da necessidade de observar implicações presentes no processo de aquisição da categoria temporal, considerando a limitação de pessoas surdas frente a um sistema de escrita fonêmico de representação de uma língua oral, cuja gramática de sua modalidade falada o aprendiz surdo não adquiriu.

Ao tipo de língua resultante do processo de aquisição de L2, Selinker (1994) tem chamado de IL, considerando esta um sistema intermediário entre a língua alvo e a língua materna. O corpus de nossa pesquisa se constituiu, portanto, do que podemos tratar como IL Português-Libras, isto é, um sistema intermediário entre a língua alvo, o PB, e a língua nativa, a Libras.

\footnotetext{
${ }^{1}$ Os dados foram produzidos por sete sujeitos-informantes, fluentes na Libras, alunos surdos das séries do Ensino Fundamental II, do Ensino Médio e um sujeitoinformante com Ensino Médio concluído, todos alunos do Colégio Estadual Abdias Menezes, no Município de Vitória da Conquista - BA, o que caracteriza esta como metodologia transversal, pelo corte realizado, e naturalística, pelo tipo de amostra. Sobre a coleta dos dados, esta se deu da seguinte maneira:

- Coleta de amostras naturalísticas da Libras, por meio de gravação em vídeo, realizadas mediante pedido feito aos informantes para que contassem um pouco de sua vida. As amostras naturalísticas da Libras foram posteriormente transcritas em SEL (Sistema de Escrita para Língua de Sinais), objetivando tornar acessível a forma articulada dos dados em Libras. Também foi feita uma versão em glosa e tradução para Língua Portuguesa de forma a tornar os dados acessíveis aos não falantes da Libras.

- Coleta de amostras naturalísticas da IL, ou seja, textos escritos em IL Português-Libras. Para tal foi pedido aos informantes surdos que escrevessem em Português a mesma história sinalizada em Libras no momento anterior. Posteriormente, foi feita uma versão em Português para os dados da IL, a fim de possibilitar a comparação entre os dados em IL com a estrutura do Português e da Libras.

Esta pesquisa foi aprovada pelo Comitê de Ética da Universidade Estadual do Sudoeste da Bahia com número CAAE 57046216.5.0000.0055.
} 
O fenômeno de aquisição da categoria Tempo ${ }^{2}$, identificado via IL Português-Libras, que foi estudado, baseou-se no quadro teórico gerativista, dentro do qual se admite a existência de uma Gramática Universal (GU) e assume-se a hipótese inatista de aquisição da linguagem. Já as discussões sobre aquisição de L2 dentro da perspectiva inatista passam necessariamente pela consideração do papel da GU nesse processo.

Sobre a marcação temporal em Libras, Finau (2004) defende que, nessa língua, o futuro tem uma estrutura estereotipada, precisando sempre de um operador temporal para ser denotado; o passado pode ter operador ou ser dado pelo Aspecto perfectivo dos verbos; e o presente é dado por default, pela ausência de marcas para passado ou futuro. Já os estudos Silva (2015) e Silva e Lessa-de-Oliveira (2016) demonstram que a marcação temporal em Libras não está reduzida aos operadores de Tempo, realizados por meio dos sinais PASSADO, HOJE, AGORA e FUTURO, mas por um sistema que faz oposição entre passado e presente, tomando por base a natureza aspectual do verbo que determina a presença ou não desses e de outros operadores de Tempo.

Sabendo que, em PB, a marcação do Tempo não se dá por meio de advérbios e/ou operadores de Tempo lexicais, mas por meio de flexão verbal, temos questionamentos a respeito do processo de aquisição da categoria temporal do PB por surdos, quais sejam: 1 . Há interferência da Libras na produção escrita do PB, caracterizando acesso indireto à GU? 2. Como se caracteriza a aquisição da categoria temporal nas produções escritas do PB por surdos?

Como respostas a essas questões, assumimos a hipótese de acesso indireto à GU, isto é, assumimos que há interferência da L1, a Libras, na aquisição da L2, o PB escrito; e assumimos ainda a hipótese da IL, conforme a qual, no processo de aquisição de uma L2, o sistema encontrado, em certo estágio, pode apresentar aspectos da L1, da L2 ou características que não correspondem nem a uma nem a outra.

\section{QUADRO TEÓRICO GERATIVISTA NOS ESTUDOS DE AQUISIÇÃO DA LINGUAGEM}

Com base na perspectiva racionalista, Chomsky defende que a criança nasce com predisposições biológicas para a aquisição de uma língua, e que uma exposição apropriada $(i n p u t)^{3}$ é suficiente para que as crianças adquiram a língua, a partir da Faculdade da Linguagem, que lhe é inata. Nesse sentido, "a Gramática Universal é um sistema que contém princípios aos quais pode estar associado algum parâmetro" (MIOTO, 1995, p.78). Nota-se que o problema do input consiste no fato de que ele "não fornece (e não tem como fornecer) informações sobre o que não é possível na língua, mas todos nós, falantes de uma língua natural, sabemos intuitiva e claramente o que é possível ou não em nossa língua” (GROLLA; SILVA, 2014, p.75).

Na concepção chomskiana, cada língua é resultado da atuação recíproca de dois fatores o "estado inicial" e a experiência. Chomsky (1981) aponta um modelo mais econômico para a aquisição da linguagem, que acontece essencialmente através da Teoria de Princípios e Parâmetros (TPP), demostrando como esse modelo teórico consegue dar conta das propriedades observadas na aquisição da linguagem.

Os princípios são leis universais, invariáveis que valem para todas as línguas naturais, os quais fazem parte da bagagem genética do indivíduo, e os parâmetros são propriedades ou conjuntos de propriedades bivalentes que podem variar de uma língua para outra, isto é, seriam a capacidade que a criança possui de definir/fixar os valores paramétricos de sua língua materna, identificando, por exemplo, se sua língua admite marcação de Tempo via flexão morfológica ou via operador lexical, por exemplo. Conforme explica Mioto (1995), essa é uma das questões que constitui o problema gerativista lógico da aquisição da língua.

Aprofundando a proposta, a versão minimalista (PM - Programa Minimalista) da teoria dos Princípios e Parâmetros (CHOMSKY, 1995) analisa que a Faculdade da Linguagem mantém relação somente com os sistemas de performance (Forma Fonética e Forma Lógica), e que a aquisição da linguagem é guiada por um princípio de economia. O PM se baseia no argumento de que a linguagem

2 Grafamos 'Tempo’ e 'Aspecto’ com inicial maiúscula sempre que esses termos representarem as propriedades formais da gramática. Isto para distingui-los de outros usos desses termos, que serão grafados com inicial minúscula.

${ }^{3}$ No contexto desses estudos esse termo significa: contato natural com a língua. 
humana pode ser um "sistema perfeito", ou seja, um sistema otimamente projetado para satisfazer condições impostas por outros sistemas cognitivos com os quais a Faculdade da Linguagem interage, conforme Chomsky (2006).

De acordo com Lopes (2001), a aquisição da linguagem, vista numa perspectiva minimalista, assume que, se a Forma Fonética e a Forma Lógica se tornam indispensáveis para a Faculdade da Linguagem, por serem interfaces do próprio sistema computacional, não só o input assume papel essencial na aquisição da linguagem, como também sua forma lógica internalizada. Desta maneira, diferentemente do primeiro e segundo momento da Teoria Gerativa, explica Lopes (2001) que a Faculdade da Linguagem é entendida no PM como encaixada nos sistemas de performance, de uma certa forma, interage com eles e deve satisfazer a condições gerais externas impostas por eles. O que Chomsky argumenta, é que, se a Faculdade da Linguagem for determinada por condições gerais independentes como simplicidade, economia, simetria, não-redundância etc., então a linguagem é um "sistema perfeito" e, como tal, ímpar entre os demais sistemas naturais.

Chomsky assume no PM uma perspectiva lexicalista, de acordo com a qual não há regras específicas a serem adquiridas, durante o processo de aquisição da linguagem, ou seja, o léxico traz informações paramétricas de uma língua específica, e o sistema computacional, por sua vez, é sensível a esse tipo de informação. "A codificação de valores paramétricos no léxico da língua é possibilitada pela concepção de que os itens lexicais são constituídos como matrizes de traços fonéticos, semânticos e formais (gramaticais)" (AUGUSTO, 2007, p.274). Dessa maneira, a aquisição teria influência disso, sobretudo no que diz respeito à parametrização.

Nesse sentido, conforme Borer (1984) apud Augusto (2007), a parametrização é resultado do conjunto de traços selecionados pelas gramáticas particulares e a sua aproximação a determinados itens lexicais (traços formais). Conforme Lourenço da Silva (2010):

A abordagem lexicalista entende que a criança, durante a aquisição da linguagem, forma um léxico mental composto por vocábulos que possuem traços formais, semânticos e fonológicos. Esse léxico fica em constante expansão mesmo após o estágio estacionário, que é o estágio de aquisição da linguagem em que o falante adquiriu uma gramatica adulta. (LOURENÇO DA SILVA, 2010, p.2)

No tocante à aquisição de segunda língua (L2), a discussão fundamental gira em torno do acesso à GU, numa perspectiva inatista. Compreendendo que a GU é a teoria da Faculdade da Linguagem inata ao ser humano, o acesso direto, parcial, indireto ou ausente a ela pode ser a explicação para as diferenças de resultado entre a aquisição de primeira (obtendo-se um falante nativo) e de segunda língua.

Observa-se que o dito Problema de Platão também se configura na aquisição de L2. Seguindo o quadro teórico gerativista, o adquirente de L2 utilizará as mesmas ferramentas, que o adquirente de L1 utiliza, ou seja, os princípios e os parâmetros da GU. “Assim como na aprendizagem da língua materna, o input disponível para o aprendiz de L2 é considerado insuficiente para que a partir dele o aprendiz consiga construir todo o sistema de uma língua” (MATTOS, 2000, p.56). Portanto, o adquirente de L2 fará o uso da GU para aquisição da segunda língua.

Mesmo estando compreendido o caráter universal dessa gramática, ainda surgem várias questões: como entender por que o resultado da aquisição de L2 não é ótimo como na aquisição de L1, e por que, por muitas vezes, a aquisição de L2 se estabiliza no que conhecemos como IL, um sistema intermediário entre a língua alvo e a língua materna, já que a GU está presente na Faculdade da Linguagem? Citamos duas justificativas defendidas pelos gerativistas como respostas a essas perguntas: a primeira está relacionada a períodos críticos de aquisição da linguagem, que compreenderiam a primeira infância e a pré-adolescência, ${ }^{4}$ e a outra justificativa, está relacionada ao acesso à GU.

\footnotetext{
${ }^{4}$ Segundo Chomsky, "Toda propriedade biológica que se conhece tem um período, no qual precisa ser ativada; depois desse período a capacidade de ativação declina acentuadamente ou pode até desaparecer” (CHOMSKY, 2008, p.78). Nesse sentido, o que Chomsky propõe é que, com a linguagem também seja assim; ele sugere que há uma linha de corte no que diz respeito à capacidade de adquirir a linguagem, por volta dos seis anos e outra na puberdade. Nas palavras de Chomsky, "essas duas transições restringem, consideravelmente a capacidade de adquirir uma segunda língua. Quando você passou de certo estágio, até pode adquiri-la, mas normalmente como uma espécie de acréscimo à língua que você já tem” (CHOMSKY, 2008, p.79).
} 
Sobre o acesso à GU, várias possibilidades são levantadas e, para cada uma das quais, procura-se justificativa para as diferenças de resultado entre aquisição de L1 e de L2: acesso total, nenhum acesso, acesso parcial, acesso dual (citados por ELLIS, 1985, apud MATTOS, 2000). Já Kato (2005) fala de acesso indireto à GU. De acordo com essa proposta, adquirentes de L2 teriam acesso direto à GU somente na marcação dos parâmetros de sua língua materna, o que poderia acarretar certos desvios na aquisição da L2, trazendo para a IL traços da sua primeira língua.

O acesso indireto à GU é também assumido por Kato (2005) para o processo de aquisição da escrita. A autora toma por base a hipótese do bilinguismo desigual de Roeper (1999) e propõe como explicação para a aquisição da escrita um processo semelhante à aquisição de L2, considerando que ocorra aí também acesso indireto à GU, no qual a modalidade falada fica na posição da L1, por via da qual se processa a aquisição de uma gramática ampliada própria da modalidade escrita. Assim, para Kato (2005), o falante letrado é um bilíngue desigual que tem, em sua Língua-I, uma periferia marcada maior do que a dos não letrados.

\section{AS CATEGORIAS TEMPO E ASPECTO}

Na gramática das línguas naturais Tempo é uma propriedade formal, que localiza o momento da ocorrência verbal em relação ao momento da produção do enunciado. Essa propriedade pode realizar-se nos sistemas gramaticais de línguas naturais por meio de diferentes mecanismos, e não somente por flexão via sufixação como ocorre em línguas como o PB. Vamos observar, neste estudo, que essa categoria funcional também pode ser realizada por um tipo de marcador temporal lexical específico ou via categoria adverbial, bem como por certas construções temporais que assumam essa função. Oliveira (2003, p.129, grifos do autor) define que "[...] a categoria Tempo serve para localizar as situações (eventos ou estados) expressas nas línguas em diferentes tipos de enunciados". Já o Aspecto, por sua vez, traz informações sobre "como é perspectivada ou focalizada a estrutura temporal interna de uma situação descrita pela frase, em particular pela sua predicação" (OLIVEIRA, 2003, p.129).

Sobre a categoria linguística temporal, Oliveira (2003) afirma que, ao analisar a forma como o Tempo é marcado nas línguas naturais, observamos que este não envolve somente a localização por meio do eixo de Tempo, pois conforme a autora, quando usamos as expressões temporais para descrever uma determinada situação, a estabelecemos por meio de um intervalo de tempo ao qual fazemos uma associação à dimensão de duração. Dessa maneira, Oliveira (2003) explica que o estudo de Tempo envolve uma ordenação de intervalo.

Como se disse, a localização temporal é relativa e nessa medida há três momentos essenciais: o ponto de fala $(\mathrm{F})$, que coincide com o momento da fala (ou da enunciação), o ponto do evento (E), que diz respeito ao ponto do acontecimento descrito pela frase, e o ponto de referência $(\mathrm{R})$, que serve como ponto intermédio a partir do qual se pode situar o evento (ou estado) descrito (OLIVEIRA, 2003, p.131, grifos do autor).

Assim como o Tempo, o Aspecto é entendido como uma propriedade elementar das línguas naturais, sobretudo pelo fato de estar diretamente ligado à duração dos Tempos verbais. Conforme Castilho (1968) apud Silva e Lessa-de-Oliveira (2016) Aspecto é a visão objetiva da relação entre o processo e o estado expressos pelo verbo, de um lado, e a ideia de duração e movimento, do outro. É, pois, a representação espacial do processo. E segundo Finau (2008), o Aspecto é responsável pela interpretação de uma ação como concluída ou não, observada na sua duração ou repetição, pois o Aspecto indica a duração do processo verbal.

A esse respeito, Oliveira (2003) apresenta uma tipologia cuja base remonta ao conceito apresentado pelo filósofo Aristóteles, quando este faz a distinção entre os verbos que denotam o ponto final (kineses) e outros que não o apresentam (energia). A primeira caracterização a ser feita sobre a tipologia aspectual começa pela distinção entre eventos e estados que se distinguem essencialmente pelo fato de o primeiro estar empregado a situações dinâmicas e o segundo não. Indo mais adiante, os eventos podem ser télicos ou atélicos, ou seja, tenderem para um fim ou não. Aos eventos télicos este ainda apresenta mais dois desdobramentos, os quais se denominam como processos culminados (duração razoavelmente longa) e culminações (duração muito breve ou nenhuma). Os processos são outro tipo de evento que se distingue dos anteriores por serem atélicos. E ainda, podemos considerar os pontos, que são eventos temporalmente indivisíveis, distinguindo-se assim das culminações, por não admitirem um estado resultante. E por fim, 
os estados que se aproximam dos processos por serem atélicos e se distanciam destes por não serem dinâmicos. Segundo Oliveira (2003) os estados não admitem qualquer pausa, enquanto que os processos admitem.

Tomando por base a tipologia aspectual apresentada acima e buscando investigar a natureza aspectual dos verbos e respectiva estrutura argumental, Brito e Duarte (2003) explicam que a caracterização dos verbos como estativos ou não (e, dentro das classes dos não estativos, a caracterização como verbos que exprimem processos, processos culminados, culminação e pontos) está estreitamente ligada ao número e a natureza de argumentos que esses verbos selecionam, como se observa na figura a seguir.

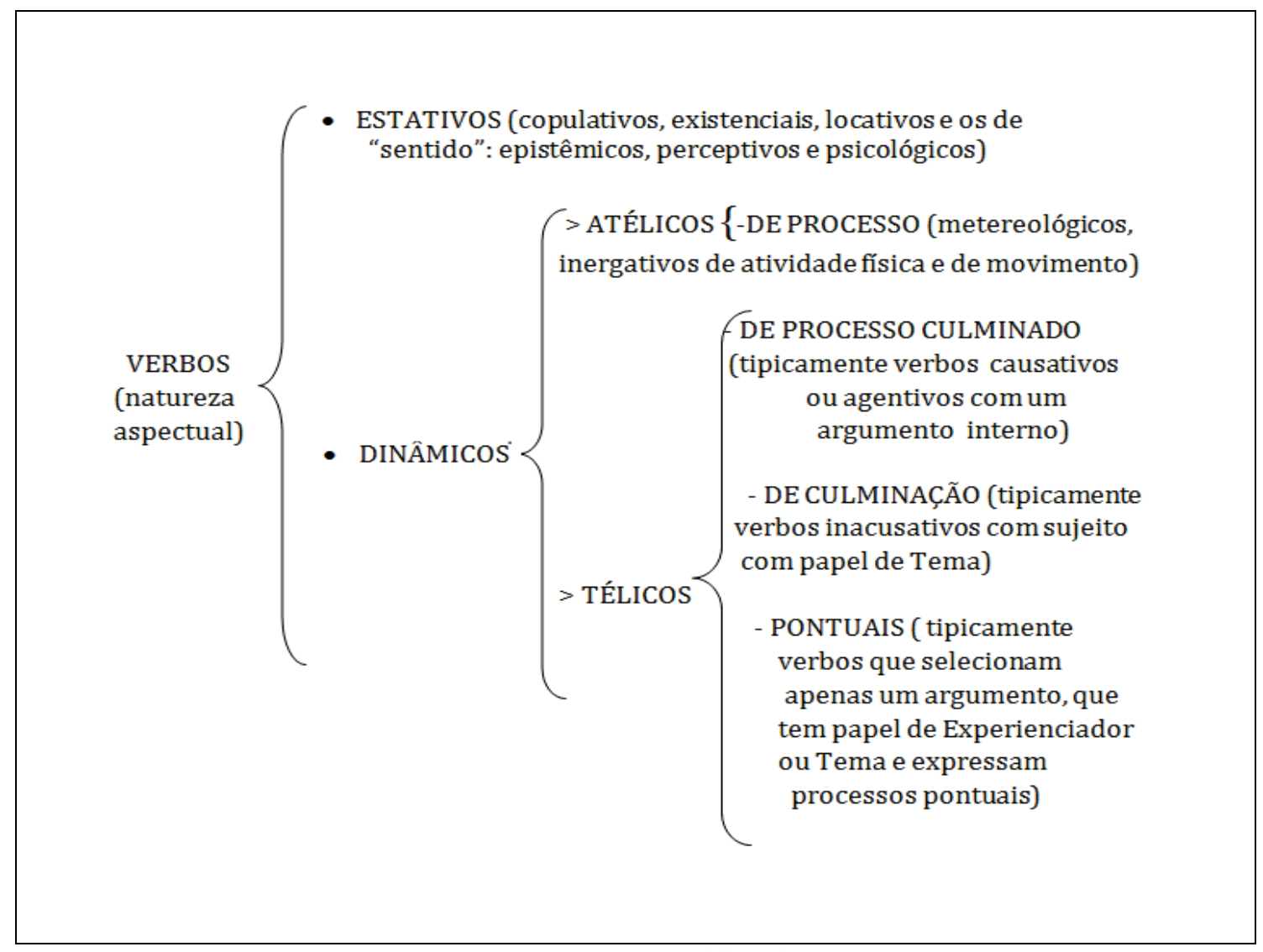

Figura 1: Natureza aspectual dos verbos

Fonte: Elaborada a partir de explanação de Brito e Duarte (2003)

\section{A CATEGORIA TEMPO EM LIBRAS}

Conforme os estudos de Finau (2008), Silva (2015), Silva e Lessa-de-Oliveira (2016) dentre outros, na Libras os verbos não sofrem flexão como em Língua Portuguesa, eles se apresentam como raízes nuas, pelo menos fonologicamente, e sua marcação de Tempo, Aspecto, Modo se apresenta a partir de elementos lexicais, como, por exemplo, o uso dos advérbios e de operadores lexicais específicos. Finau (2004) admite a possibilidade de afixação em contexto específico, isto é, uma espécie de afixação sequencial, considerando a possibilidade de existirem afixos aspectuais marcados por características específicas dos movimentos que modificam a raiz dos sinais verbais. No entanto, apesar dessa característica de ausência de flexão, pelo menos via morfologia explícita, na língua de sinais, Silva e Lessa-de-Oliveira (2016, p.162) explicam que isso “[...] não significa dizer que os traços abstratos, que comumente se manifestam como morfemas funcionais nas línguas orais, não estejam presentes nas línguas de sinais”.

Sobre a marcação temporal, Felipe (1998) e Ferreira (2010) consideram a hipótese de marcação temporal dos verbos em Libras por meio de elementos lexicais. As autoras afirmam que a referência temporal nessa língua seria dada sintaticamente por meio dos advérbios na linha temporal. Nessa perspectiva, o Tempo é marcado sintaticamente pelos advérbios de tempo, ou seja, tais advérbios indicam se a ação está ocorrendo no presente: HOJE, AGORA; ocorreu no passado: ONTEM, ANTEONTEM; ou se irá ocorrer no futuro: AMANHÃ. Observa-se que os advérbios vêm sempre no começo ou final das frases, marcando o Tempo em que se fala. E 
para Tempos verbais indefinidos, usam-se os sinais HOJE, PASSADO e FUTURO para trazerem respectivamente a ideia de presente, passado e futuro (SILVA, 2015).

Já para Finau (2008), a hipótese defendida é que as sentenças têm sua temporalidade marcada pela composição entre aspectos e fatores pragmáticos. Ou seja, a autora defende que: "[...] o futuro tem uma estrutura estereotipada, precisando sempre de um operador temporal para ser denotado; o passado pode ter o operador ou ser dado pelo aspecto perfectivo dos verbos; e o presente é dado por default ${ }^{5}$, justamente pela ausência de marcas para o passado ou futuro." (FINAU, 2008 apud SILVA; LESSA-DEOLIVEIRA, 2016, p.3).

Sobre a marcação temporal dos verbos em Libras, Felipe (1998), Finau (2008) e Ferreira (2010) afirmam que também pode ser realizada pela propriedade aspectual e não somente pelo uso de advérbios ou operadores. As propriedades aspectuais podem ser identificadas por marcas, tais como: repetições de sinais verbais, amplitude e intensidade do movimento, processos não manuais como expressão facial, por exemplo.

A partir das considerações feitas até aqui sobre o valor temporal na Libras a partir de itens lexicais, Finau (2008) observa que, nessa língua, há diferentes marcas temporais dos eventos que se dão no passado e no futuro, as quais podem ser diferenciadas com intervalos mais abertos ou fechados; logo, trazendo a ideia de que sentenças não marcadas por esses intervalos que representem o passado e o futuro devem ser entendidas como ocorrendo no presente. A autora explica que a temporalidade também pode ser marcada pela lexicalidade dos verbos e de seus complementos, já que o Tempo está também relacionado com as propriedades aspectuais das sentenças.

Silva (2015) verificou que, em certa medida, a hipótese de Finau (2008), que prevê que o presente é dado por default, porque é interpretado pelo falante mediante ausência de marcas para o passado ou futuro, não se aplica ao corpus de sua pesquisa, pois, segundo a autora, os surdos pesquisados por ela produziram sentenças com ausências de marcas temporais para o passado, embora essas sentenças não sejam compreendidas como realizações do Tempo presente, mas sim de Tempo passado. Nesse sentido, Silva (2015) afirma que sentenças feitas no passado também dispensam marcas temporais, se se realizam num contexto onde se verifica o Aspecto pontual do verbo, o qual garante a essa sentença a compreensão de evento ocorrido no passado e não em outro Tempo. Em (1) fica demonstrado o que Silva (2015) defende, uma vez que o verbo 'nascer' não possui uma marca de passado articulada como 'ontem', 'anteontem', por exemplo. No entanto, pelo contexto e Aspecto pontual do verbo entendemos como uma ação concluída.

(1)

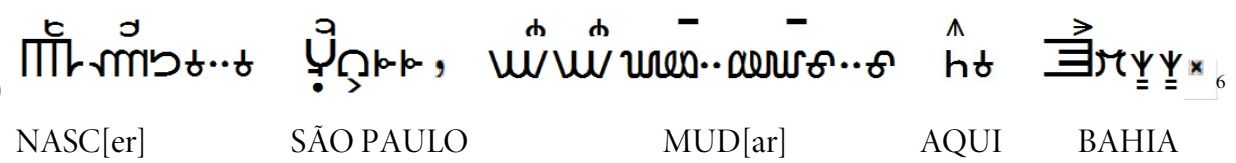

'Eu nasci em São Paulo, depois mudei aqui para Bahia.'

(adaptado ${ }^{7}$ de SILVA; LESSA-DE-OLIVEIRA, 2016, p. 172)

Dessa forma, Silva (2015), buscando uma análise para a questão anteriormente apresentada, parte da ideia de que entidades localizadas na dimensão temporal são aquelas compostas pelos estados, processos e eventos (Cf. COSTA, 1990) e defende que:

[...] com base numa Âncora Temporal Lógica, concretamente, os eventos e processos só existem no passado. No presente, os eventos e processos não estão completos e, quando se completam, tornam-se passado. O mesmo se

\footnotetext{
${ }^{5}$ A característica default considerada pela autora consiste na ausência de operador articulado, isto é, morfema zero. Não devemos entender aqui, default como uma propriedade da GU.

${ }^{6}$ As amostras da Libras, apresentadas neste texto, foram transcritas em SEL (Sistema de Escrita para Língua de Sinais), objetivando tornar acessível a forma articulada dos dados em Libras. O Sistema de escrita foi produzido por Lessa-de-Oliveira (2012). Utilizamos para a transcrição a versão atualizada em Lessa-de-Oliveira (2018). Para informações sobre a escrita SEL consultar o Blog Escrita SEL em: http://sel-Libras.blogspot.com.br/.
}

${ }^{7}$ As adaptações dos dados em Libras de Silva e Lessa-de-Oliveira (2016) dizem respeito apenas à atualização da escrita SEL, adequando-a à versão 2018 desse sistema. 
pode dizer dos eventos e processos futuros, que não têm sua existência concretizada, a não ser quando estejam completamente no passado. Nessa perspectiva podemos considerar o traço [Precedência] dentro de certa Âncora Temporal Lógica que se baseia na [Dêixis] temporal. Por lógica, o traço [Inteireza] se associa ao traço de [Precedência], pois para ser verdadeiramente precedente o evento ou processo precisa estar inteiro, completo, concluído (SILVA, 2015, p.109).

Essa discussão também se fundamenta no que apresenta Freitag (2005), segundo a qual a [Precedência] e a [Inteireza] são traços relacionados ao Tempo, ou seja, "[...] o traço [Precedência] estabelece relação [...] entre uma sentença e sua âncora temporal e o traço [Inteireza] requer a relação de precedência para estabelecer relação entre todos os momentos do evento e a âncora temporal" (FREITAG, 2005, p.422). Nesse sentido, "a propriedade [Inteireza] refere-se à continuidade de uma ação, se foi concluída ou não, e a propriedade [Precedência] mantém relação com o sistema temporal das línguas" (SILVA; LESSA DE OLIVEIRA, 2016, p.5).

Sobre o sistema de marcação temporal na Libras, que mantém relação com uma Âncora Temporal Lógica, Silva e Lessa-de-Oliveira (2016) afirmam que esse se estabelece da seguinte maneira:

\begin{abstract}
Assim, por nossa análise, o sistema de marcação temporal que se estrutura na Libras parte de uma Âncora Temporal Lógica, que associa: o passado marcado (isto é, com a presença de operadores marcados) à presença do traço [Precedência] somente; o passado não-marcado à presença dos traços [Precedência]+[Inteireza]; o presente marcado à presença do traço [Inteireza] somente; e o presente não-marcado à ausência de qualquer desses traços (SILVA; LESSA-DE-OLIVEIRA, 2016, p.12).
\end{abstract}

Dessa maneira, essa proposta para o sistema de marcação temporal em Libras, conforme as autoras, se dá a partir dos traços aspctuais que determinam uma distribuição complementar entre os Tempos passado e presente, que se apresentam como marcados ou não, por um lado, e uma posição diferenciada do futuro, sempre marcado, por outro, como se verifica no quadro a seguir.

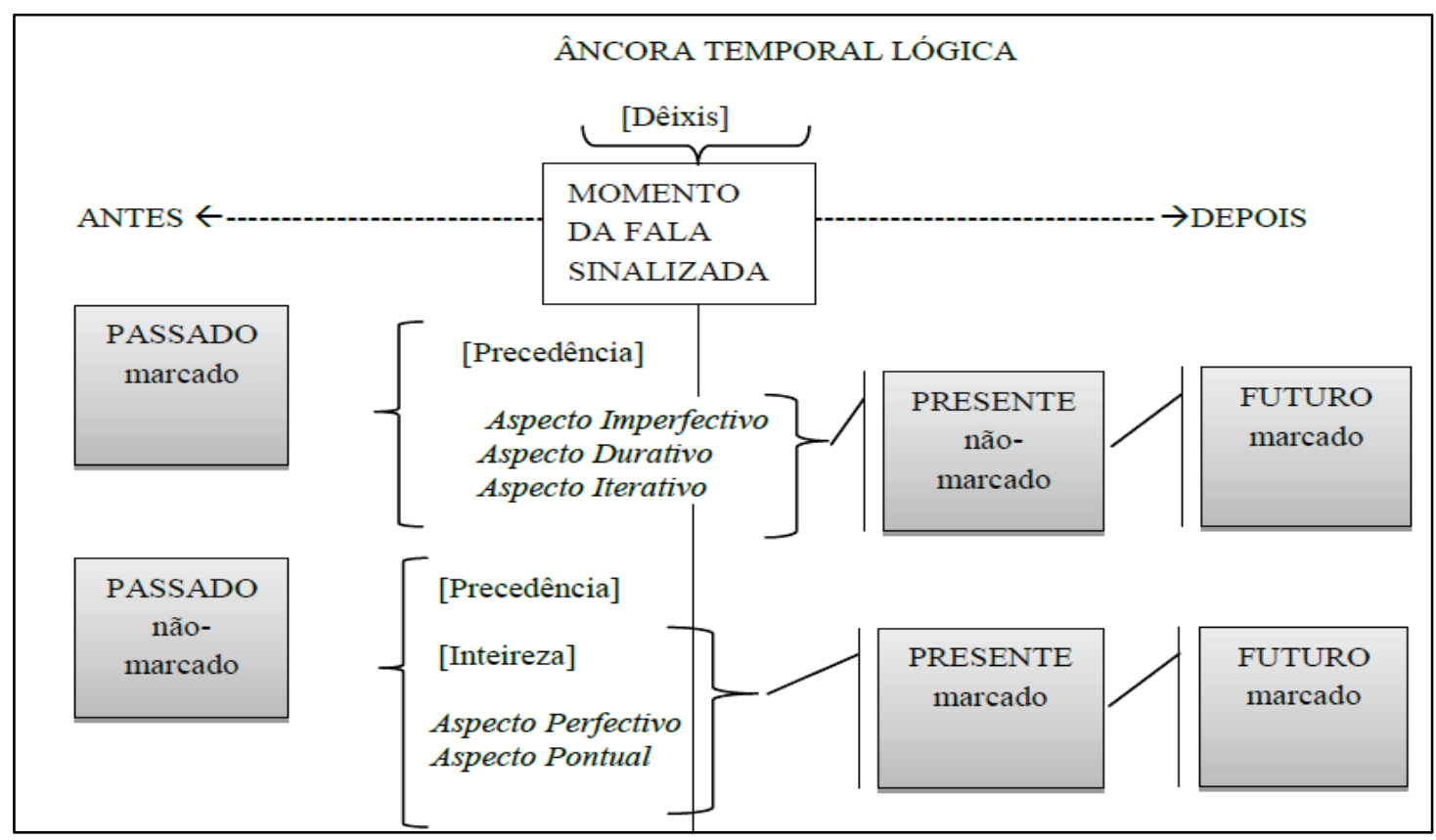

Figura 2: Traços envolvidos na marcação de Tempo em Libras

Fonte: Silva (2015, p. 114)

Por essa análise, a presença do traço [Inteireza] torna a marcação de Tempo no passado desnecessária, no âmbito de uma Âncora Temporal Lógica, e a ausência dele torna desnecessária essa marcação para o Tempo presente. Como o futuro, nessa lógica, está muito aquém da [Inteireza], considerando a lógica de que, ao se completar, o fato se coloca no passado, o Tempo futuro fica com a obrigatoriedade de marcação temporal. 


\section{A CATEGORIA TEMPO NO PB ESCRITO POR SURDOS}

Assumindo que, no processo de aquisição de L2, o adquirente pode se encontrar em diferentes estágios de interlíngua, tratamos o PB escrito realizado por pessoas surdas, aqui investigado, por IL. Nos tópicos a seguir, nos ocupamos da investigação dos mecanismos utilizados na escrita de IL para a marcação temporal. Para análise dos dados, tomamos por base os estudos de Finau (2004; 2008), de acordo com os quais o futuro é sempre denotado por operador temporal, o passado pode ter operador ou ser dado pelo Aspecto perfectivo dos verbos e o presente é dado por default, pela ausência de marcas para passado ou futuro; e indo mais adiante, nos apoiamos principalmente nos estudos Silva (2015) e Silva e Lessa-de-Oliveira (2016), que partem do pressuposto de que a marcação temporal em Libras não está reduzida aos operadores adverbiais de Tempo, mas se constitui via sistema que faz oposição entre passado e presente, baseada na natureza aspectual do verbo e em operadores de Tempo presentes ou ausentes. Desta forma, tomando como ponto de partida a natureza aspectual dos verbos, procuramos verificar: se o que ocorre nas sentenças da IL investigada é uma marcação temporal via advérbio, via operadores temporais lexicais específicos ou via natureza aspectual, compatibilizando a IL investigada com o sistema da Libras; ou se ocorre uma marcação temporal via morfemas flexionais, seguindo parâmetros do PB. É importante salientar que os dados apresentados são sentenças de IL e a categoria Tempo pode acontecer seguindo critérios da Libras, do PB ou de nenhuma dessas línguas. Assim sendo, a tarefa aqui posta é verificar quais são os mecanismos que operam a propriedade de Tempo nessa escrita da IL Português-Libras de surdos, podendo acontecer também por mecanismos singulares, o que caracterizaria uma estrutura própria da IL.

Assim sendo, a análise dos dados implicou avaliar se as ocorrências temporais apresentaram, sintaticamente, características da Libras ou do PB. Como se observa a seguir, os dados de nosso estudo trazem evidências que não somente revelam a interferência da Libras no PB adquirido como L2 por surdos, constituindo-se como evidência a favor da hipótese de acesso indireto à GU, como também confirmam as propostas de Finau (2004) e, sobretudo, de Silva (2015) e Silva e Lessa-de-Oliveira (2016), porque trazem evidência de que o surdo, adquirindo uma L2, traz para a segunda língua os parâmetros de um sistema baseado no Aspecto verbal; mas não somente, encontramos, na produção desses informantes, a mesma oposição entre passado e presente com e sem marca de Tempo a depender do Aspecto concluso ou inconcluso do verbo. Mas, por outro lado, os dados também revelam marcas do sistema flexional de marcação de Tempo do PB.

\subsection{MARCAÇÃO DE TEMPO PASSADO - VIA OPERADOR LEXICAL, COMO EM LIBRAS}

No dado (2) a seguir, produzido por nosso sujeito-informante 1 (INF1), temos um verbo de Aspecto inconcluso numa frase em que se procura expressar um fato ocorrido em tempo anterior ao momento da fala, portanto, no $<<$ passado $>>$.

(2) / passado Ano 2008 estuda/ (INF1)

$/(\mathrm{No})$ ano (de) 2008 estud[ei]/

'Eu estudei em 2008.'

Como podemos observar, em (2), temos o verbo 'estudar', que é um verbo não pontual, não concluso. O verbo da frase aparece aí flexionado na $3^{\text {a }}$ pessoa do presente do indicativo. No entanto, considerando o contexto pragmático, a sentença está no passado. Observamos que o referido verbo aparece sem morfemas flexionais para marcação de Tempo passado e, na sentença, há um elemento que desempenha essa função, o item lexical 'passado', diferentemente do que ocorre em PB. Além disso, o contexto pragmático em que foi coletado esse dado indica que a pessoa do discurso seria a $1^{\text {a }}$ e não a $3^{\text {a }}$. Devemos também considerar um possível erro na escrita, havendo a possibilidade de esse estar em sua forma infinitiva, 'estudar', como comumente se verifica na IL Português-Libras. O surpreendente é que verificamos que esse item lexical, da forma como aparece, no início da sentença e sem

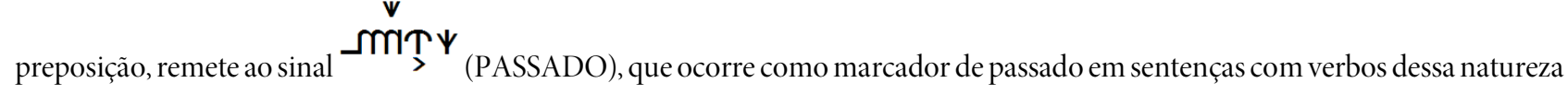
em Libras, como 'morar', conforme o exemplo de Silva e Lessa-de-Oliveira (2016) abaixo: 


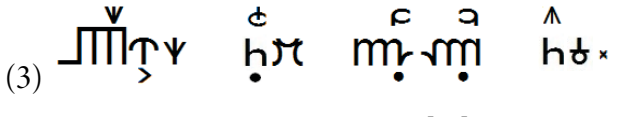

PASSADO EU MOR[ar] AQUI.

'Eu morava/morei aqui'.

(adaptado de SILVA; LESSA-DE-OLIVEIRA, 2016, p.174)

Observamos em (2) que o DP (Sintagma Determinante) 'Ano 2008' assume na sentença a função de Adjunto a VP (Sintagma Verbal), representando assim, a circunstância temporal (lembrando que em PB esse seria um PP, Sintagma Preposicional), que não pode ser necessariamente identificada como passado. Só pragmaticamente se pode verificar se 2008 seria anterior, posterior ou o ano correspondente ao momento da fala. Já o acréscimo do item lexical 'passado' pode ser identificado na sentença como um operador temporal que marca o Tempo, uma vez que nessa sentença esse item é o único responsável pela marcação de Tempo passado. Verificamos aqui uma característica que se assemelha à Libras com base em duas análises. Segundo Finau (2008), o item 'passado' na Libras é considerado um operador temporal específico, ocorrendo nas sentenças como marcador de Tempo. E, conforme a análise de Silva e Lessa-de-Oliveira (2016), o verbo 'estudar' em Libras implica a presença de um marcador de Tempo passado porque não é pontual ou concluso, traço aspectual também verificado nesse exemplo da IL.

\subsection{MARCAÇÃO DE TEMPO PASSADO - VIA ASPECTO VERBAL, COMO EM LIBRAS}

Diferentemente de (2), no exemplo a seguir, realizado por INF4, não há marca alguma de Tempo, pois o verbo está no infinitivo e não há outra marca de Tempo, embora o contexto pragmático indique que esta é uma sentença elaborada para informar sobre uma ação que está no passado.

(4) /Nascer Vitoira da conquista./ (INF4)

/Nasc[i] (em) Vitória da Conquista./

'Nasci em Vitória da Conquista.'

Observando o verbo pelo seu Aspecto, verificamos se tratar de um verbo pontual, configurado no âmbito dos verbos télicos, portanto concluso. Sobre a característica lexical do verbo 'nascer', Finau (2008, p.279) com base em análise do sinal da Libras, afirma que "ao ser empregado sem nenhuma marca temporal, não é interpretado como presente, mas como passado, devido à temporalidade inerente ao verbo". Silva (2015) explica que a característica aspectual do verbo 'nascer' ressalta e expressa uma ação realizada em um ponto específico no tempo com interpretação perfectiva pontual, implicando aí os traços de [Precedência + Inteireza]. Silva (2015) ainda chama a atenção para o fato de que "mesmo que se empregue um sinal como HOJE, junto com NASCER, a situação pode ser interpretada como futuro ou passado [...], pois o Aspecto perfectivo se mantém” (Ibidem, p.279). Portanto, encontramos nesse dado da IL, (4) acima, o mesmo tipo de marcação de passado via Aspecto concluso, perfectivo, pontual, encontrado em dados da Libras como (5), realizado pelo INF3.

(5)

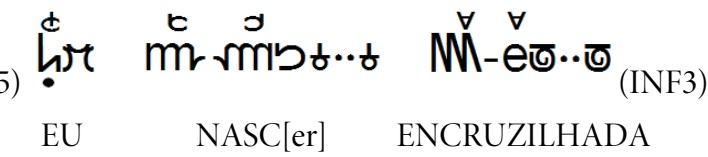

'Eu nasci em Encruzilhada.'

\subsection{MARCAÇÃO DE TEMPO PASSADO - VIA ASPECTOS PRAGMÁTICOS, COMO EM LIBRAS}

Diferente da marcação via item lexical verificada anteriormente, a seguir verificaremos que em (6) a marcação do Tempo é realizada por outro mecanismo. Verificamos neste dado, produzido por INF6, a realização do verbo 'estudar', sem morfemas flexionais de Tempo nem marcadores como 'passado', encontrado no exemplo (2). 
(6) /Estudar Roça so Portugues/ (INF6)

/(Eu) etuda[va](,) (na) roça(,) só Portugue(ê)s/

'Eu estudava, na roça, só Português.'

Em (6) o item '(na) roça' parece assumir a marcação temporal da sentença, não obstante o fato de este trazer um traço locativo em vez de temporal. Ou seja, '(na) roça' funciona aí como uma expressão referente a um lugar onde INF6 esteve em um tempo anterior, já mencionado no texto, isto é, um momento passado, no qual se deu o ato de estudar Português. Finau (2008) considera, como já dissemos, que, além do Aspecto verbal, aspectos pragmáticos participam da marcação de Tempo em Libras. Em (6) podemos verificar a atuação de fator pragmático na identificação do Tempo sentencial, em que um adjunto locativo passa a funcionar como um marcador temporal. Como vemos, esse dado da IL estudada também revela presença de características do sistema de marcação de Tempo mais próximo ao que ocorre em Libras do que ao sistema de marcação via morfemas flexionais do PB.

\subsection{MARCAÇÃO DE TEMPO PRESENTE - VIA ASPECTO VERBAL, COMO EM LIBRAS}

No corpus, foi possível identificar a realização do Tempo presente de dois modos distintos - via itens lexicais (responsáveis pela marcação temporal), bem como pela ausência desses itens lexicais. Primeiramente, partimos da identificação dos verbos a partir de sua natureza aspectual e verificamos se eles aparecem ou não com marcas do Tempo presente. Após essa constatação, verificamos se há itens lexicais responsáveis pela marcação de Tempo nas sentenças, identificando se são advérbios ou operadores temporais específicos, como em Libras, ou se são simplesmente modificadores (adjuntos), assumindo função de caracterização do processo verbal.

Os dados em (7) são amostras de IL em que não aparecem morfemas flexionais de Tempo nem operadores temporais lexicais específicos ou advérbios. Pelo contexto geral do texto e informações pragmáticas sobre o momento de produção deste (o informante fala de sua situação presente como aluno no CEAM - Colégio Estadual Abdias Menezes), sabemos tratar-se de uma sentença no Tempo presente.

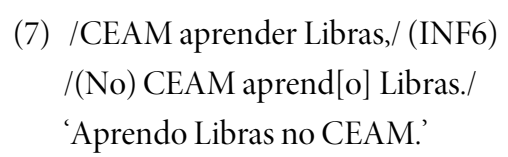

Observamos que nessa sentença temos o verbo 'aprender', um verbo estativo, ou seja, um verbo não pontual. Assim, verificamos proximidade com o sistema de marcação de Tempo da Libras, tanto conforme o que afirma Finau (2008), que acredita que a ausência de marcação do Tempo presente seja pelo fato de esse ter caráter default em Libras, quanto conforme Silva (2015) e Silva e Lessa-de-Oliveira (2016), segundo as quais a marcação do Tempo presente na Libras sem operadores temporais se dá devido ao Aspecto não pontual do verbo, como se observa no exemplo a seguir.

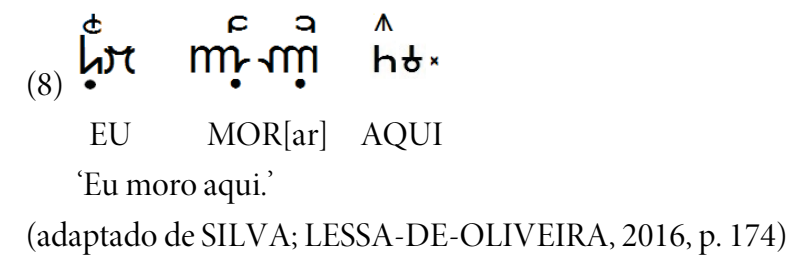

\subsection{MARCAÇÃO DE TEMPO PRESENTE - VIA OPERADOR LEXICAL, COMO EM LIBRAS}

No próximo dado verificamos não haver morfema flexional de Tempo e verificamos a ocorrência de um advérbio de tempo - agora.

(9) /agora começar ser palavras/(INF3)

/agora começ [o](a) ser (ter/aprender) (as) palavras(.)/

'Agora começo a aprender as palavras.' 
Como podemos observar, nessa sentença aparecem dois verbos de natureza distintas - 'começar', que se caracteriza aspectualmente como um verbo incoativo (marca o ponto inicial do processo), e o verbo 'ser', um estativo. Sobre esse último, nota-se que há uma dificuldade de adequação semântica, pois não é possível entender a sentença 'começar ser palavras'. Entendemos que houve aí, possivelmente, um problema de seleção lexical; isto é, com base no sentido global do texto, entendemos que houve uma possível troca de verbos existências (ter por ser). Ao que parece, como análise mais plausível, isto pode estar relacionado ao fato de que "[...] verbos estativos em Libras como os copulativos, existenciais, e alguns psicológicos comumente não ocorrem de forma articulada" (SANDES-DA-SILVA, 2016, p.96). Nesse sentido, a troca do item lexical se torna justificável, já que em sua língua nativa é incomum a realização articulada desses verbos, fazendo o adquirente surdo do PB realizar um pelo outro em contextos de preenchimento com verbos existenciais.

Prosseguindo com nossa análise, se os verbos da oração matriz não trazem morfemas flexionais que indiquem Tempo, como em $\mathrm{PB}$, e é de Aspecto incoativo, o item 'agora' pode ser identificado como o único responsável por atribuir Tempo presente ao verbo 'começar', como ocorre em Libras. Ao que parece, estamos analisando uma sentença subordinada e, em PB, o infinitivo ocorre em sentenças subordinadas, como é o caso do verbo 'ter' (ser), mas não em sentenças matrizes, como é o caso do verbo 'começar', precisando este verbo de flexão de Tempo. Dessa forma, 'agora' pode ser identificado como o operador temporal da sentença.

Já na sentença em (10) abaixo, produzida pelo informante 4, temos uma situação um pouco diferente. Ocorre nessa o verbo 'entender', que não apresenta morfema flexional de presente e o verbo tem Aspecto imperfectivo. Quanto ao item 'pricisa' (precisa), que aparece nesse exemplo, podemos analisá-lo ou como o particípio na subordinada 'entendo que é preciso', ou como forma nominal semelhante a 'ter a precisão ou necessidade de’. Ambas as análise estão de acordo com a interpretação geral do texto. Optamos pela segunda possibilidade por parecer sintaticamente mais próxima do que foi produzido.

\section{(10) /hoje sim entender pricisa/ (INF4) \\ /hoje sim entend[o] (a) precis[ão]/necessidadel \\ 'Hoje sim entendo a necessidade'}

Como vimos, de acordo com o que propõem Silva (2015) e Silva e Lessa-de-Oliveira (2016), em Libras a marcação do Tempo presente implica a presença de marcadores temporais se o Aspecto do verbo for perfectivo, pontual. Já com verbos de Aspecto imperfectivo, durativo, a marcação do Tempo presente fica por conta do Aspecto verbal. Assim, se em (10) o verbo 'entender' não apresenta morfema flexional de presente, não vemos nesse exemplo o sistema de marcação temporal do PB. Por outro lado, se esse verbo tem Aspecto imperfectivo, é possível estar ocorrendo, nesse exemplo, aproximação com o sistema da Libras, pois o item 'hoje’ pode estar ocorrendo nessa oração apenas como adjunto adverbial, ficando a marcação temporal de presente por conta do Aspecto imperfectivo do verbo 'entender'. É o que ocorre em exemplos da Libras como (11) a seguir, em que, conforme a proposta de Silva (2015) e Silva e Lessa-de-Oliveira (2016), o Tempo presente é marcado, em sentenças como essa, pelo Aspecto imperfectivo do verbo, que dispensa marcador de Tempo lexical, no presente. Dessa maneira, o sinal HOJE funciona, nesse contexto sintático, apenas como adjunto adverbial. E pela própria interpretação que podemos fazer de 'hoje’ nas sentenças (10) e (11), verificamos que há um peso semântico desses advérbios mesmo nas estruturas em PB, que também trazem a marcação de Tempo flexional. Se eliminamos esse item, perdemos a referência deles a um tempo físico referente ao discurso e não ao Tempo sintático.

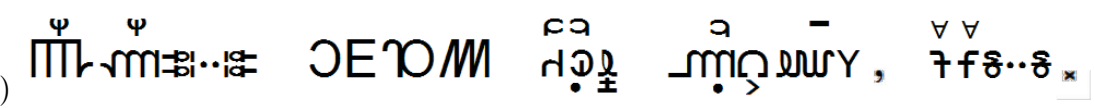

HOJE CEAM PALAVRA SAB[er] FELIZ

'Hoje, no CEAM, eu sei as palavras, estou feliz.'

Todavia não há como afirmar, com certeza, que estejam presentes em (10) parâmetros de marcação da Libras, pois há também a possibilidade de estarmos diante de um sistema de marcação alternativo, próprio da IL, que não corresponde nem ao PB nem à Libras, no qual marcadores temporais lexicais aparecem independentemente do Aspecto verbal. 
Analisando a sentença abaixo, verificamos que a marca de Tempo futuro é realizada pelo item 'futuro' que se mostrou indispensável para localização de um ponto específico no tempo, ou seja, esse item é que indica que as ações serão realizadas posteriormente ao momento da fala; logo, dando a ideia de futuro. Além de a sentença vir com a marcação de Tempo estereotipada, seguindo critérios da Libras, ainda carece de preenchimento de itens lexicais como os verbos 'sentir' (psicológico não causativo) e 'ser' (copulativo), que, considerando a sua natureza aspectual, são verbos estativos e funcionais, o que ratifica a premissa de acordo com a qual traços da língua materna estão presentes na IL.

(12) /futuro Saudade legal/ esenobar estuda não quero./ (INF1) ${ }^{8}$

/(Sentirei) saudades (do) (que) (foi) legal/ não quero esenobar (o) estud(o)a./

'Sentirei saudades do que foi legal, não quero esnobar o estudo.'

Observamos que, em (12), o operador 'futuro’ não apenas localiza temporalmente a sentença, como também realiza a marcação de Tempo do verbo 'sentir', que na sentença não aparece realizado. Na Libras, o verbo 'sentir' não é realizado foneticamente, mas é entendido pelo sinal daquilo que quer expressar o sentimento, ou seja, não se realiza um sinal para SENTIR e outro para SAUDADE, mas o sinal SAUDADE funciona também como um verbo, o que semanticamente é entendido como 'sinto saudade'. Então, na sentença (12), considerando que o operador que marca o Tempo é $<<$ futuro $>>$, interpreta-se 'saudade' como um verbo que significa 'sentirei saudade’. Outro verbo que também não é realizado na sentença é o verbo 'ser' (também não é realizado foneticamente, em Libras, como já dissemos), isto é, observamos que, além do item 'futuro' atribuindo a marca de Tempo à sentença, ocorre nessa sentença também verbos nulos, o que caracteriza fortemente a IL estudada como apresentando traços da Libras.

Abaixo, trazemos um exemplo da realização do Tempo futuro na Libras, feito pelo informante 4, a fim de compararmos os parâmetros de marcação de Tempo da IL com os da Libras.

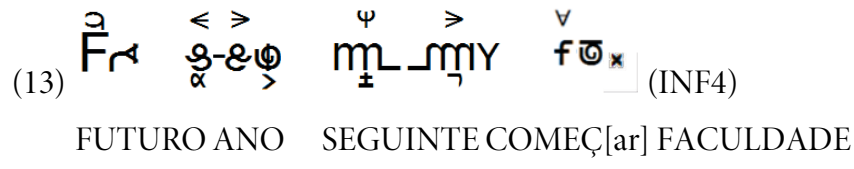

'No ano que vem começarei a faculdade.'

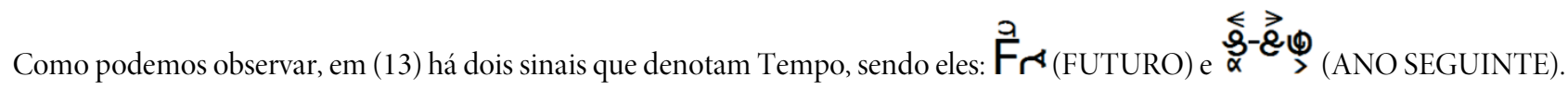

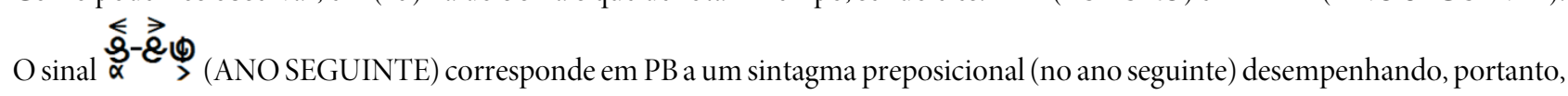
a função de adjunto adverbial de tempo. Embora seja uma expressão de tempo, este não é o responsável na sentença pela marcação do traço de Tempo, já que existe aí um item, o sinal $\mathrm{F}_{\text {\} } \text { (FUTURO), que é um operador temporal específico. Nesse sentido, o }$ sintagma 'ano seguinte' ocorre em (13) como adjunto do VP 'começar'. Verificamos, portanto, o mesmo tipo de marcação de Tempo entre a sentença (12) da IL estudada e a sentença (13) em Libras.

\subsection{MARCAÇÃO DE TEMPO FUTURO - VIA VERBO AUXILIAR, COMO EM LIBRAS}

No corpus da pesquisa também foi possível identificarmos sentenças em que não aparecem operadores temporais como o item 'futuro', como visto anteriormente. Em vez disso verificamos outros mecanismos operando esse Tempo. Vejamos:

\footnotetext{
${ }^{8}$ Nesse exemplo estamos considerando apenas a primeira sentença como exemplo de futuro realizado como em Libras, pois na segunda se realiza o presente flexionado do PB.
} 
(14) /fazer trabalha vai futuro./ (INF7)

/vou fazer trabalh[os] (no) futuro./

'Vou fazer trabalhos no futuro'

(15) /Os eu vai Escola ler./ (INF7)

/Os (outros) (e) eu va[mos] ler (na) escola./

'Os outros e eu vamos ler na escola'

Observamos o verbo auxiliar de futuro nos dados (14) e (15), realizado pelo informante 7. Entretanto, há uma diferença entre este e o verbo auxiliar realizado em PB para marcação de Tempo futuro, que normalmente aparece anteposto ao verbo principal e flexionado no presente do indicativo com concordância número-pessoal com o sujeito, o que caracteriza o futuro como Tempo composto. Já em (14) o auxiliar aparece em terceira pessoa e posposto ao verbo principal, e em (15) mesmo anteposto ao verbo, aparece sem concordância com o sujeito, o que remete ao auxiliar da Libras V-A-I (em datilologia ${ }^{9}$ ).

Verificamos, assim, que (14) e (15) apresentam a forma de futuro com auxiliar, da Libras, pois o Tempo futuro em Libras também se realiza com um verbo auxiliar, além do operador 'futuro' ou advérbios de tempo. É importante observar que, já que "vai” está funcionando como marcador de Tempo futuro em (14), o item "futuro" é interpretado como um adjunto nessa sentença, como "no

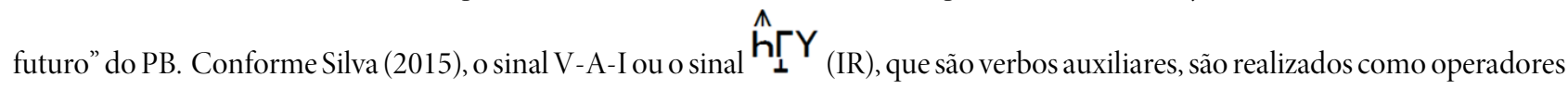
de Tempo, marcando o Tempo futuro. Como veremos nos exemplos apresentados pela autora.

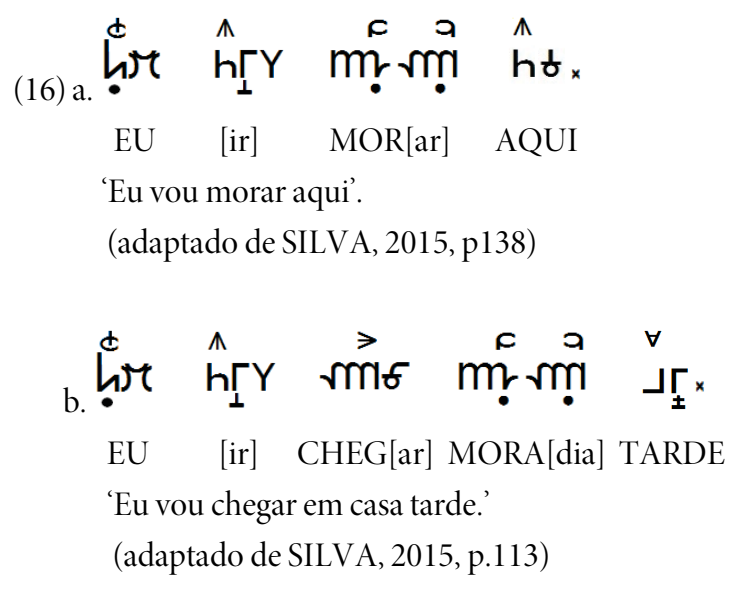

\subsection{MARCAÇÃO DE TEMPO PASSADO - VIA MORFEMAS FLEXIONAIS, COMO EM PB}

Neste grupo de dados, observamos que o informante 2, conforme vemos na sentença (17), utiliza parâmetros da língua alvo (PB) para a marcação de Tempo, ou seja, faz uso de morfemas flexionais, bem como do advérbio de tempo 'hoje' como modificador do verbo 'passar', seguindo assim os parâmetros do PB.

(17) / professor passou uma disciplins educação hoje/ (INF2)

/(O) professor passou uma disciplin(a)s (sobre) educação hoje(.)/

'O professor passou uma disciplina sobre educação hoje.'

Observe que, na sentença acima, o verbo traz a marca de Tempo 'passado' representada por morfema flexional acrescido ao radical da palavra, o qual, numa estrutura arbórea, subiria do núcleo de VP para checar o traço de Tempo no núcleo de IP (Sintagma Flexional). Enquanto que o advérbio de tempo 'hoje', por sua vez, é sintaticamente interpretado como adjunto adverbial nessa sentença, trazendo uma circunstância de tempo ao processo verbal.

${ }^{9}$ Espécie de soletração que ocorre em Libras como empréstimo linguístico do Português. 


\subsection{ARCAÇÃO DE TEMPO FUTURO - VIA VERBO AUXILIAR, COMO EM PB}

Nos dados, foi possível identificar sentenças em que a marcação de futuro não ocorre via flexão verbal. A marcação de Tempo, nessa sentença, se dá por meio do auxiliar 'ir', que apresenta flexão para presente do indicativo, formando o que é caracterizado pela gramática tradicional como futuro em forma de Tempo composto, em PB.

(18) /vou trabalha estudar sempre/ (INF4)

/vou trabalha[r] (e) estudar sempre(.)/

'Vou trabalhar e estudar sempre.'

Em (18) a distinção entre advérbio como marcador temporal e como modificador do verbo se acentua, nela o advérbio 'sempre' aparece como modificador do verbo 'estudar', ocorrendo como adjunto de VP, dando a ideia de continuidade e não como marca de Tempo.

\subsection{MARCACÃO DE TEMPO PRESENTE - VIA MORFEMA FLEXIONAL, COMO EM PB}

Na sentença abaixo, escrita pelo informante 3, o item 'agora' aparece mais uma vez realizado, no entanto este assume uma função distinta da de operador temporal. Vejamos a sentença:

(19) /agora libras tem feliz muito/(INF3)

/Agora (que) tem libras(,) (estou) muito feliz (.)/

'Agora que tem libras, estou muito feliz.'

(20) / Meu nome é Heloisa/(INF3)

/Meu nome é Heloisa(.)/

'Meu nome é Heloisa.'

Em (19) notamos a existência de dois verbos estativos, o existencial 'ter', que já aparece com marcas de flexão para o Tempo presente, e o copulativo 'estar', que não aparece lexicalmente realizado. Consideramos que essa não realização do 'ser' está associada ao fenômeno do copulativo nulo, verificado comumente em Libras. Então, verificamos que o item 'agora' na sentença pode ser interpretado como adjunto adverbial porque na sentença ocorre uma marca flexional de Tempo para o verbo 'ter', não havendo necessidade, assim, de outro operador de Tempo. Já em (20), diferentemente, o fenômeno do copulativo nulo, comum em Libras, não se repete. O informante 3 realiza o verbo ‘ser’ flexionado adequadamente, seguindo os parâmetros do PB.

\subsection{MARCAÇÃO DE TEMPO PASSADO - VIA PROCESSO MISTO ENTRE O SISTEMA DA LIBRAS E O SISTEMA DO PB}

Analisando agora a sentença (21) e ainda nos debruçando sobre a aspectualidade do verbo como característica indispensável para marcar o Tempo em Libras, observamos um processo misto entre o sistema da Libras, conforme a proposta de Silva (2015) e Silva e Lessa-de-Oliveira (2016) e o sistema do PB.

(21) / começou atras/ familia chegar já sumir saudades/ (INF3)

/(Tudo) começou (lá) atrás/ (minha) família chaga[va] (e) já sum[ia](.) (Eu) (sentia) saudades(.)/

'Tudo começou lá atrás, minha família chegava e já sumia. Eu sentia saudades.'

Como podemos observar, os verbos 'chegar' e 'sumir' que aparecem nas sentenças acima são de natureza perfectiva, expressando um processo pontual. Nesse caso, em Libras, o "tempo de referência pode ser interpretado como um todo ocorrido antes do momento de fala” (FINAU, 2008, p.270). Já o verbo 'começar’ é de Aspecto incoativo ou inceptivo, portanto percebemos o começo, 
mas não o fim do processo. Observando o dado da Libras em (22), produzido pelo mesmo informante do dado (21), verificamos que, nessa sentença, que traz o verbo incoativo 'começar' e os verbo durativos 'estudar' e 'aprender', não ocorre marca de passado e a sentença é interpretada no passado. COMEÇ[ar] PALAVRA ESTUD[ar] ESTUD[ar]
'Comecei a estudar muito as palavras e fui aprendendo.'

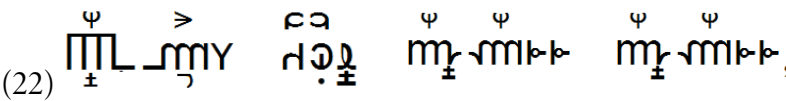

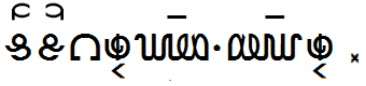 APREND[endo]

A análise que fazemos desse dado é que também verbos incoativos apresentam o traço [Inteireza], que se associa ao traço [Precedência], ${ }^{10}$ marcando o passado em Libras aspectualmente. o verbo 'estudar' está nesse dado numa subordinada, que no PB corresponde ao infinitivo. Já o verbo 'aprender', interessantemente, ocorre com articulação diferente do padrão, pois foi articulado com movimentos circulares alternados na direção da testa do emissor. Compreende-se aí um traço [Durativo] à moda do gerúndio do PB. Ou seja, parece que temos nessa forma alternativa de articulação do sinal APRENDER uma flexão de gerúndio, via alteração do movimento. ${ }^{11}$

Observamos, em (21), que não há ausência completa de marca de Tempo, como no exemplo da Libras em (22). Ocorre em (21) um morfema flexional de passado apenas no verbo 'começar'. Além disso, aprece o advérbio 'atrás', que está estabelecendo também uma referência temporal específica de passado para a sentença. Segundo Finau (2008, p.275) o "tempo referência também faz parte da organização aspectual".

Podemos fazer a seguinte análise desse dado. Como a marca flexional de passado apareceu em 'começar' e o passado desse verbo em Libras dispensa presença de operador, como vimos em (22), tem-se, em (21), o caso de um terceiro sistema, próprio da IL, em que, independentemente do Aspecto verbal, um único operador de Tempo (podendo ele ser um morfema flexional idêntico ao do PB) é suficiente para colocar toda a sentença complexa no passado, dispensando flexão nos demais verbos.

Outro exemplo de marcação de Tempo que segue parâmetros de ambas as línguas, Libras e PB, é o que se vê no dado (23), vejamos:

(23) /Quando era menirno Roça gosta jogar bola/ (INF6)

/Quando era menirno(,) gosta[va] (de) jogar bola (na) roçal

'Quando era menino, eu gostava de jogar bola na roça.'

O exemplo (23) traz uma sentença complexa subordinada. Nela, temos lexicalmente realizados verbos de natureza estativa - 'ser' (copulativo), 'gostar' (epistêmico) - e de natureza dinâmica - 'jogar' - que se caracterizam como não pontuais e atélicos. Observamos que 'ser' aparece com marcas de flexão para Tempo passado conforme o PB, enquanto que 'gostar' ou aparece flexionado na $3^{\text {a }}$ pessoa do singular do presente do indicativo (e considerando o contexto pragmático da sentença está flexionado incorretamente, pois deveria estar na $1^{\text {a }}$ pessoa) ou deve estar na forma infinitiva, como comumente ocorre em IL, e houve um erro ortográfico. Se consideramos essa última hipótese, poderemos entender que a flexão de passado do verbo 'ser', nessa sentença, também marca o Tempo do verbo 'gostar', que não aparece com morfemas de flexão para Tempo, pois ocorreu no infinitivo. Considerando os dados apresentados anteriormente, analisamos que o que se tem é um terceiro sistema, próprio da IL, diferente da Libras e do PB, pois o que observamos nesses casos é, por um lado, a presença de uma única marca de passado, suficiente para colocar toda a sentença no passado, como em Libras, mas que necessariamente não está se pautando na aspectualidade, diferentemente

\footnotetext{
${ }^{10} \mathrm{O}$ ponto inicial do processo verbal é que é o foco aspectual desses verbos. Esse ponto fica logicamente no passado, uma vez que, ao avançar, o processo deixa seu ponto inicial sempre para trás, completamente no passado.

${ }^{11}$ Conforme explica Silva (2015, p, 103), “alguns sinais em libras parecem fazer essa marcação aspectual com um alongamento do movimento”. Para Ferreira (2010) e Felipe (1998) o Aspecto ocorre em Libras como um fenômeno de afixação por meio da alteração do movimento, da configuração de mão e/ou do ponto de articulação do verbo. Entretanto, Silva (2015) observa que essa alteração ou alongamento no movimento para determinar duração e término de um evento não é produtivo em Libras, ocorrendo ocasionalmente.
} 
desta; e, por outro lado, a presença de um morfema flexional de Tempo como em PB, mas apenas em um dos verbos, diferentemente deste.

Quantitativamente, observamos no corpus investigado, conforme tabela abaixo, que a maior parte das sentenças apresentou parâmetros do sistema de marcação de Tempo em Libras, 45\%, ocorrendo marca do sistema do PB apenas em 25\% dos casos, o que denota um estágio de aquisição ainda bastante distante da língua alvo. O Tempo passado foi o único a apresentar o sistema misto, com concentração de 67\%; o Tempo futuro apresenta-se marcado quase que apenas pelos parâmetros da Libras, 92\% dos casos; e o Tempo presente se distingue dos demais por apresentar maior concentração do parâmetro do sistema do PB.

Tabela 1: Distribuição de marcas de Tempo na IL Português-Libras

\begin{tabular}{c|c|c|c|c|c} 
& $\begin{array}{c}\text { Dados } \\
\text { brutos }\end{array}$ & $\begin{array}{c}\text { Total de } \\
\text { sentenças }\end{array}$ & Passado & Presente & Futuro \\
\hline Parâmetros do PB & 10 & $25 \%$ & $17 \%$ & $60 \%$ & $8 \%$ \\
\hline Parâmetros da Libras & 18 & $45 \%$ & $16 \%$ & $40 \%$ & $92 \%$ \\
\hline Sistema misto & 12 & $30 \%$ & $67 \%$ & $0 \%$ & $0 \%$ \\
\hline Total & 40 & $100 \%$ & $100 \%$ & $100 \%$ & $100 \%$
\end{tabular}

Fonte: dos Autores

\section{CONCLUSÃO}

A partir da incursão conceitual que fizemos no decorrer deste estudo e análise empírica da IL, pudemos verificar que a categoria Tempo pode se apresentar de maneira distinta nas línguas naturais humanas, evidenciado, assim, a variação paramétrica hipotetizada por Chomsky.

Em Libras, a marcação do Tempo, conforme vimos a partir dos estudos de Finau (2004, 2008), se realiza por advérbios e operadores temporais específicos representados pelos sinais PASSADO, HOJE, AGORA e FUTURO, englobando também a natureza aspectual do verbo. Silva (2015) e Silva e Lessa-de-Oliveira (2016), por sua vez, defendem que a marcação de Tempo também está relacionada à natureza aspectual do verbo, havendo um sistema de distribuição complementar entre passado e presente a depender do aspecto perfectivo ou imperfectivo do verbo. Já em $\mathrm{PB}$, a marcação temporal se realiza por meio de morfemas flexionais acrescidos aos radicais verbais.

Por meio de análise de produção escrita de surdos, pudemos verificar que o processo de aquisição de L2 pode se caracterizar com traços da língua nativa, da língua alvo, ou de nenhuma delas. A IL dos informantes deste estudo apresentou, no geral, características da língua nativa (Libras). Na escrita do PB (L2), a marcação temporal se realizou via operadores de Tempo, advérbios e aspectos pragmáticos, e essa marcação lexical esteve intimamente ligada ao Aspecto verbal, conforme se verifica na Libras. No entanto, houve também uma produção, ainda que tímida, com parâmetros do PB, isto é, verbos flexionados, e ainda produções com características mistas, ou seja, apresentando traços da Libras e do PB. Nesse sentido, os dados evidenciam que a IL pode se compor de vários níveis, mais próximos ou distantes da língua alvo.

Enfim, tais evidências confirmaram a nossa hipótese inicial de acesso indireto à GU, ou seja, que a aquisição da categoria Tempo em PB escrito, como segunda língua, por surdos, apresenta interferência da L1, a Libras, que leva os surdos a apresentarem, em suas produções escritas, além de flexão verbal, como ocorre na língua alvo (o PB), também, em certas circunstâncias, um tipo de marcação de Tempo que envolve Aspecto verbal mais marcador temporal lexical específico ou categoria adverbial ou ainda aspectos pragmáticos. 


\section{REFERÊNCIAS}

AUGUSTO, M. R. A. Aquisição da linguagem na perspectiva minimalista: especificidades e dissociações entre domínios. In: VASCONCELLOS, Z.; AUGUSTO, M. R. A.; SHEPHERD, T. M. G. (org.). Linguagem, teoria, análise e aplicações (3). Rio de Janeiro: Letra Capital, 2007, p. 269- 283.

BORER, H. The Projection of Arguments, Functional Projections, University of Massachusetts Occasional Papers 17, 19-47, 1984.

BRITO A. M.; DUARTE. I. Predicação e classe de predicadores verbais. In: MATEUS, M. H. M. et al. Gramática da Língua Portuguesa. 63.ed., revista e aumentada. Lisboa: Caminho. 2003, p. 179-204.

CASTILHO, A. T. Introdução ao estudo do aspecto verbal na língua portuguesa. Marília: Faculdade de Filosofia, 1968.

CHOMSKY, N. Lectures on government and binding. Dordrecht: Foris, 1981.

CHOMSKY, N. The minimalist program. Cambridge, MA: MIT Press, 1995.

CHOMSKY, N. Sobre a natureza e linguagem. Organizado por Adriana Belletti e Luigi Rizzi. Trad. Marylene Michael. São Paulo: Martins Fontes, 2006.

CHOMSKY, N. Arquitetura da linguagem. Organizador por Nirmalangshu Mukherji, Bibudhendra Narayan Patnaik e Rama kant Agnohot. Tradução de Alexandre Morales e Rafael Ferreira Coelho. Bauru, SP: EDUSC, 2008.

COSTA, S. B. B. O aspecto em português - Coleção Repensando a Língua Portuguesa. São Paulo: Contexto, 1990.

ELLIS, R. Understanding second language acquisition. Oxford: Oxford University Press, 1985.

FELIPE, T. Relação sintático-semântica dos verbos e seus argumentos na LIBRAS. 1998. 195 f. Tese (Doutorado em Linguística) Universidade Federal do Rio de Janeiro, Rio de Janeiro, 1998.

FERREIRA, L. Por uma gramática de língua de sinais. Rio de Janeiro: Tempo Brasileiro, 2010.

FINAU, R. A. Os sinais de tempo e aspecto na libras. 2004. 233 f. Tese (Doutorado em Letras) - Universidade Federal do Paraná, Curitiba, 2004.

FINAU, R. A. As marcas linguísticas para a categoria tempo e aspecto na Libras. In: QUADROS, R. M. de. Estudos Surdos III - Série pesquisas. Petrópolis, RJ: Arara Azul, 2008, p. 258-297.

FREITAG, R. M. K. Arranjos dos traços da flexão verbal no Português. Estudo Linguísticos XXXIV, p. 421-426, Garopaba, Universidade Federal de Santa $2005 . \quad$ Disponível em: http://www.gel.org.br/estudoslinguisticos/edicoesanteriores/4publica-estudos 2005/4publica-estudos-2005-pdfs/geometria-dostracos-233.pdf. Acesso em: 12 jan. 2017.

GROLLA, E.; SILVA, M. C. F. Para conhecer aquisição da linguagem. São Paulo: Contexto, 2014.

KATO, M. A. A gramática do letrado: questões para a teoria gramatical. In: MARQUES, M. A. et al. (org.). Ciências da linguagem: trinta anos de investigação e ensino. Braga: CEHUM, 2005, p. 131-145. 
LESSA-DE-OLIVEIRA, A. S. C. Libras escrita: o desafio de representar uma língua tridimensional por um sistema de escrita linear. Revel, v. 10, n. 19, 2012. Disponível em: http://www.revel.inf.br/files/6cf381ab909eeed796b069253a14d5ad.pdf. Acesso em: 12 set. 2016.

LESSA-DE-OLIVEIRA, A. S. C. Escrita SEL - Sistema de Escrita para Língua de Sinais (Blog). Disponível em: http://selLibras.blogspot.com.br. Acesso em: 10 maio 2018.

LOPES, R. Aquisição da linguagem: novas perspectivas a partir do programa Minimalista. DELTA, São Paulo, v.17, n.2., p. 245-281, 2001. Disponível em: http://www.scielo.br/scielo.php?pid=S0102-44502001000200004\&script=sci abstract\&tlng=pt. Acesso em: 29 set. 2018.

LOURENÇO DA SILVA, E. O advento da Morfologia Distribuída. ReVEL, v. 8, n. 14, 2010. Disponível em: http://www.revel.inf.br/files/artigos/revel 14 o advento da morfologia distribuida.pdf. Acesso em: 05 maio 2017.

MATTOS, A. M. A. A hipótese da gramática universal e a aquisição de segunda língua. Rev. Est. Ling., Belo Horizonte, v.9, n.2, p.5171, jul./dez. 2000. Disponível em: http://periodicos.letras.ufmg.br/index.php/relin/article/view/2325. Acesso em: 15 nov. 2017.

MIOTO, C. A gramática gerativa e aquisição de linguagem. Letras de Hoje, Porto Algre. v.30, n. 4, p.75-81, dez. 1995.

OLIVEIRA, F. Tempo e aspecto. In: MATEUS, M. H. M. et al. Gramática da Língua Portuguesa. 63. ed., revista e aumentada. Lisboa: Caminho. 2003, p. 127-178.

ROEPER, T. Universal Bilingualism. Bilingualism: Language and Cognition. v.2, n.3, p.169-186, dez, 1999.

SANDES-DA-SILVA, J. M. A categoria verbal em interlíngua Português-Libras: aquisição da modalidade escrita do Português por surdos. 2016. 99 f. Dissertação (Mestrado em Linguística) - Programa de Pós-Graduação em Linguística, Universidade Estadual do Sudoeste da Bahia, Vitória da Conquista, 2016.

SELINKER, L. Rediscovering interlanguage. (Applied linguistics and language study). London: Longman, 1994.

SILVA, I. B. O. A categoria dos verbos na Língua Brasileira de Sinais. 2015. 152 f. Dissertação (Mestrado em Linguística) - Programa de Pós-Graduação em Linguística, Universidade Estadual do Sudoeste da Bahia, Vitória da Conquista, 2015.

SILVA, I. B. O.; LESSA-DE-OLIVEIRA, A. S. C. Propriedades funcionais verbais na Língua Brasileira de Sinais, Revista Linguística - Teoria Sintática, v. 12, n. 2, 2016. Disponível em: https://revistas.ufrj.br/index.php/rl/article/view/5473/6219. Acesso em: 21 julho 2018.

\section{()(1) $\circledast$}

